\author{
Military Technical College \\ Kobry El-Kobbah, \\ Cairo, Egypt
}

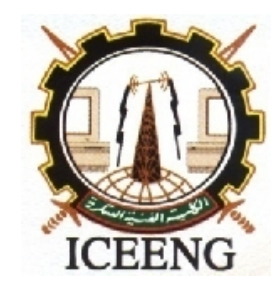

\author{
$8^{\text {th }}$ International Conference \\ on Electrical Engineering \\ ICEENG 2012
}

\title{
Evaluation of a Smart-Wire Approach for Congestion Management in Electrical Power Systems with Wind Generation
}

\begin{abstract}
By
A. Elmitwally*

Abstract:

This paper presents the distributed series reactor (DSR) as a low cost D-FACTS technology that can be easily clamped on working transmission lines at higher operational reliability and without the need of any communications or centralized control. Smart wires are standard transmission lines that are augmented with a large number of DSRs. The paper addresses the potential of the emerging smart wire technology in improving the utilization and reliability of the existing transmission, sub transmission, and distribution networks. It proposes a smart-wire based strategy for planning power systems with increasing penetration level of wind generation. Moreover, the paper evaluates the potential of the smart-wire technology to reduce the required investment for congestion-free transmission system upgrading plan. The proposed approach is applied to the IEEE 39-bus and IEEE 57-bus test systems. Comparative analysis of results is provided for the classic and smart planning methods.
\end{abstract}

\section{Keywords:}

D-FACTS, smart-wire and transmission system upgrading

*Elect. Eng. Dept., Mansoura University, Mansoura 35516, Egypt 


\section{Introduction:}

Increasing societal concern for global warming and energy security has led many of the US states to adopt policies like Renewable Portfolio Standards (RPS). Introduction of these environmental policies in the energy market are expected to have significant impact on grid operation and transmission investment. The energy delivery system has to be upgraded significantly to make it capable of handling these changes [1]-[6].

Utility system planners are moving from radial towards networked systems to achieve higher reliability. This has degraded the controllability of the network, as current flow along individual lines can no longer be controlled. The transfer capacity of the system gets limited by the first line that reaches the thermal capacity. Congestion on key corridors restricts the low-cost generators to connect to the end users, resulting in higher electricity prices for the consumers [2], [3].

An RPS mandates a specified percentage of the electricity production to be generated from renewable resources. Some states can meet the RPS mandate in either of two ways. The first is self generation of this part of renewable energy. The second is purchasing power from renewable generators in other states via bilateral contracts. This is because it might not be economically feasible to build in-state renewable generation facilities. The choice is to purchase green energy from other renewable-energy rich states to meet the RPS mandates. Therefore, increased penetration of renewable energy will cause increased inter-area power transactions. Due to the geographical dispersion, the interstate tie-lines are often very long. So, they require large capital investment for installation and upgrade [2]-[5].

The increasing operational dynamics due to liberalized electricity markets, and growing load have pushed the existing grid to unusual levels of stress. Moreover, investments in the transmission and distribution infrastructure decay gradually. Further, it has become increasingly tough and expensive to construct new power lines. Accordingly, the aging power-grid has become congested and highly stressed. The grid has two approaches to solve this severe problem. The first is the traditional method of building extra transmission assets. The second is making the grid smart and controllable. The latter option receives a lot of attention as a major feature of 21 st century power system [7][10].

Many papers have addressed the problem of congestion management in power systems [11] - [17]. Different solutions have been presented including generation re-dispatching, load curtailment, optimal power flow (OPF), and flexible ac transmission devices (FACTS) [12], [14]. The application of Static Series Synchronous Compensator (SSSC) as inverter-based FACTS for congestion management and transfer capability improving of power systems with high penetration of wind power is studied in [16]. Ref. [13] presents a genetic algorithm (GA) to maximize total system social welfare and alleviate congestion by best placement and sizing of thyristor-controlled series capacitor (TCSC) 
device. Ref. [5] has recently presented the smart-wire concept as an efficient and economic solution to control congestion in multi-area power systems integrating growing production levels of wind energy. However, the analysis has only considered congestion in inter-area lines ignoring possible congestion in intra-area lines. No clear mechanism was given to remove encountered congestion.

This paper presents the distributed series reactor (DSR) as a low cost D-FACTS technology that can be easily clamped on working transmission lines at higher operational reliability and without the need of any communications or centralized control. Smart Wires (SW) are standard transmission lines that are augmented with a large number of DSRs. The paper addresses the potential of the emerging SW technology in improving the utilization and reliability of the existing transmission, sub transmission, and distribution networks. It proposes a SW based strategy for planning power systems with increasing penetration level of wind generation as a major economic source of renewable energy. Moreover, the paper evaluates the potential of the SW technology to reduce the required investment for congestion-free transmission system upgrading plan. The proposed approach is applied to the IEEE 39-bus and IEEE 57-bus test systems. The impact of varying the size and location of wind generation on the details of transmission upgrading plan is also assessed.

\section{$\underline{\text { 2. Power Flow Control and Smart Wires: }}$}

The real power through a transmission line is given by (1).

$$
P_{12}=\frac{V 1 V 2 \sin (\delta 1-z 2)}{X 12}
$$

where $V_{1}, V_{2}$ are the voltage magnitudes while $\delta_{1}, \delta_{2}$ are the voltage phases of the two ends of the line and $\mathrm{X}_{12}$ is the line impedance, assuming the line is lossless [3].

By controlling the voltages and/or the line impedance it is thus possible to control the power flowing through the line directing the power through the lightly loaded lines. A number of power flow controllers were proposed over the past two decades. Most of them belong to FACTS [3] - [5].

\subsection{Distributed FACTS}

FACTS devices have proved to significantly increase the transfer capacity and the utilization of the power system. However, their commercial success has been limited [4], [8]. The reliability of the technology can be increased and the cost can be decreased, if the same control objective is served by replicating the big controller into smaller ones and distributing them over the grid. Thereby, the concept of Distributed FACTS (D-FACTS) was proposed by Divan, et al [4], [9]. It consists of single 
phase devices that can clamp onto existing conductors, providing easy installation procedure. However, being an inverter-based technology, it opens up issues of robust and reliable operation in tough utility environment. Further, a communication infrastructure is essential for the coordinated operation of the modules on the network. This may hinder the wide spread application of the technology.

2.2 Distributed series impedance

A Distributed Series Impedance (DSI) is similar to D-FACTS devices. It injects series VARS into the line by injection of series impedance (inductor or a capacitor) [9], [10].The transfer capacity and consequently the grid utilization can be improved by routing the power flow from overloaded lines to underutilized parts of the network. The series injection of impedance at each module can be accomplished using a single turn transformer (STT), which uses the line conductor itself as a winding of the transformer. Figure 1 shows the circuit schematic of a DSI module. The STT is normally bypassed by the normally-closed electro-mechanical switch $S_{M}$. Opening $S_{M}$ allows injection of the desired impedance into the line. Switch $S_{1}$ is closed to inject an overall inductance, while $S_{2}$ is closed to inject capacitance $X_{C}$. A control circuit is powered off the line, and monitors the line current [9].

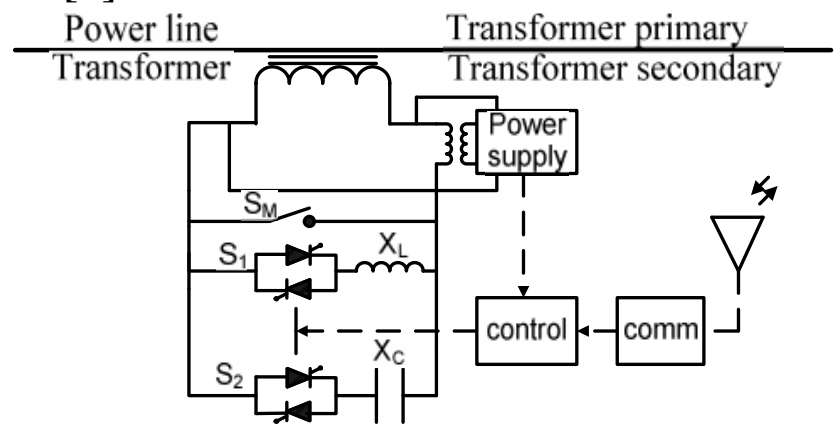

Figure (1): Circuit schematic of DSI

\subsection{Distributed series reactance}

Bidirectional control capability of DSI requires a communication interface to instruct the device to operate in the particular mode. It is desired to make the modules switch in or out without the need for centralized control. This can be done if the control is made unidirectional, and the amount of injection is decided according to locally measured current and/or voltage. Pure inductive injection has this characteristic [3], [5]. This implementation is referred to as the Distributed Series Reactance (DSR). It can only inject reactive impedance to increase the line impedance. Figure 2 shows the circuit schematic of a (DSR). A normally closed electromechanical switch $\left(\mathrm{S}_{\mathrm{M}}\right)$ is used to bypass the module when it is not desired. With $\mathrm{S}_{\mathrm{M}}$ open, the STT magnetizing inductance (tuned to a desired value) is inserted into the line. $S_{1}$ is a thyristor switch used to provide a sub-cycle response [10]. 


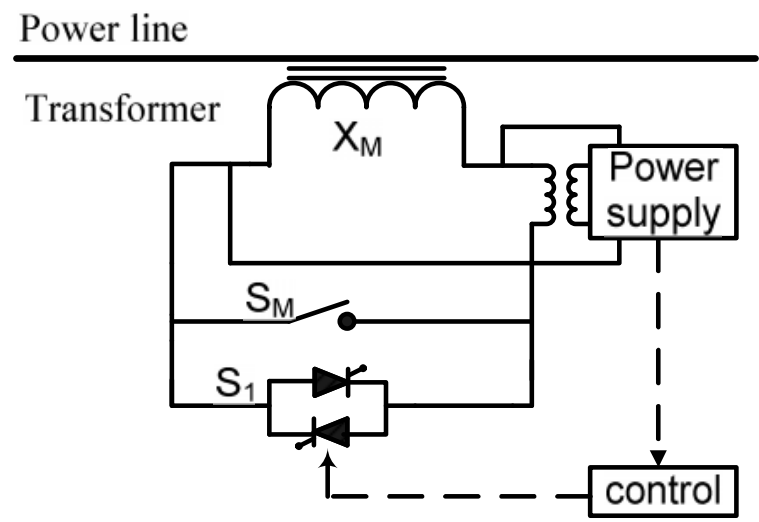

Figure (2): Circuit schematic of DSR

Because SW are equipped with a large number of DSRs, they are thus capable of dynamically changing their self impedance by switching on/off certain number of DSRs as shown in Figure 3 [5], [10]. When the current in a particular line exceeds a preset value, increasing numbers of DSR modules are switched in. They gradually increase line impedance and divert current to under-utilized lines. This securely pushes the system to its maximum power transfer capacity. Also, it allows the system to share the overload between lines enhancing reliability by avoiding unnecessary tripping of overcurrent relays. Thus a self-healing network can be obtained.

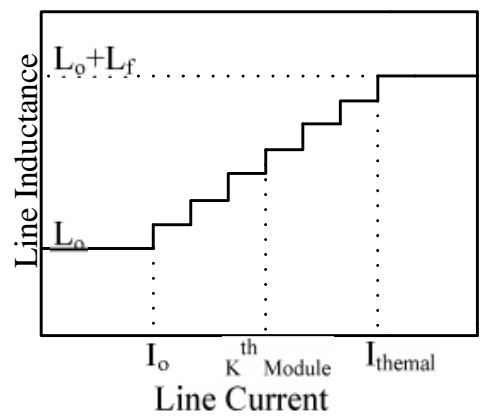

Figure (3): Increasing impedance of smart wires with line current

\section{Simulation Setup:}

To examine the transmission investment benefits achieved by the use of SW for implementation of RPS, a study was conducted on the IEEE 39 bus system with 10 generators version [18] and with 11 generators version [5]. It is assumed that the entire system is divided into 4 regions - the North East (NE) region, the North West (NW) region, the South West (SWT) region and the South East (SE) region which are broadly representative of a multi-area interconnection. Figure 4 shows the demarcations outlining the different regions in the IEEE 39 bus system. It is assumed that the system at present (year 0 ) has a renewable penetration of $1 \%$ and the RPS mandate requires it to reach $20 \%$ in 19 years with increments of $1 \%$ each year [5]. 


\subsection{Assumptions}

Given that wind energy is presently the cheapest form of renewable energy, it is assumed as the source of renewable energy for the entire system. It is assumed that only NW region is rich in wind energy. Thus, the entire amount of renewable energy required by the 4 regions is supplied from the NW region at buses 30 and 37. All other generators in the system use fossil fuel [5], [10].

\subsection{Modeling load and wind generation}

The wind generators and the loads are each assigned an intra-day variation characteristic as shown in Figure 5. The load variations of the four utilities are calculated for each of 6 time steps, as a percentage of the peak loading. It is assumed that two wind generators follow different intra-day variation characteristics. Daily profiles were taken from NREL's eastern wind integration and transmission study. It is assumed that there is no change in the intra-day variation of load or wind generation within a year. As the study is concerned with transmission planning, the worst case day (highest load, lowest wind generation) is chosen as the representative day of the year [1], [10].

The total initial peak load of the system is $6380 \mathrm{MW}$. It is assumed that the peak loads at each bus increase at an annual rate of $2 \%$. The wind generation at year 0 is assumed to be $1 \%$ of the total load [5].

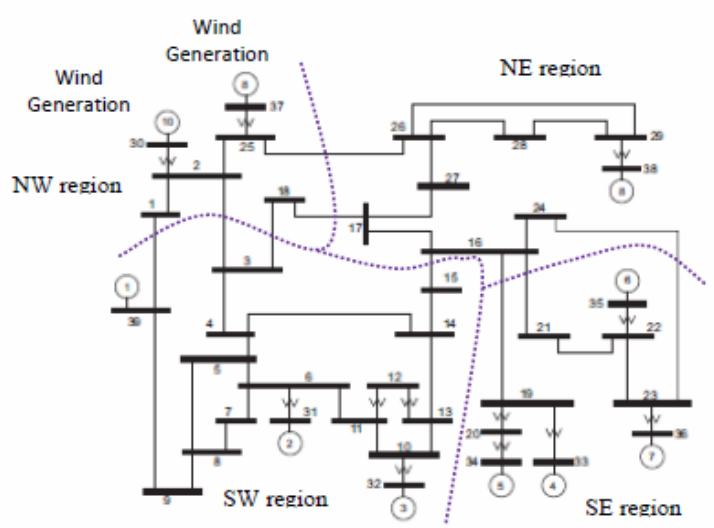

Figure (4): IEEE 39 bus system with the regional demarcation

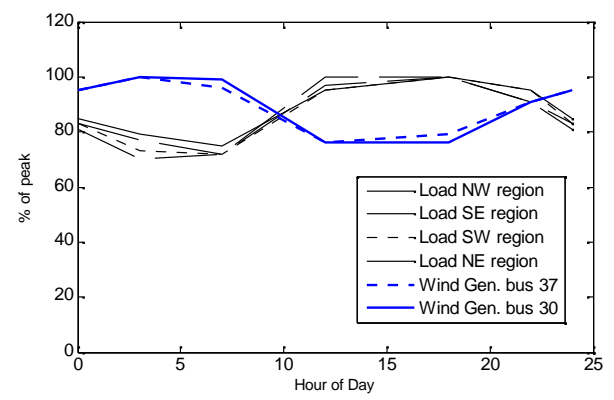

Figure (5): Daily variations of loads and wind availability 


\section{Simulation Methodology:}

4.1 System planning algorithm

For each of the 20 years planning horizon, starting from year 0 , the loadings of the load buses and the available wind generation for the wind buses are determined according to section 3.2, for each of the 6 time steps defined in Figure 5. To enable wind plants to meet revenue requirements, it is assumed that all the available wind generation at any time step must not be curtailed due to congestion. An optimal power flow (OPF) is run for each of the time steps to check for any line congestion. This is done using the MATLAB-based open source software MATPOWER [19]. If congestion is encountered, it is treated by one of the two line upgrade scenarios as described in section 4.2 below. The system planning algorithm is summarized in the flow chart shown in Figure 6.

\subsection{Congestion management scheme}
A. Line upgrade in BAU scenario

In the business as usual (BAU) scenario, the utility upgrades a congested line by building a new line of the same rating parallel to it [1], [5]. Hence, the rating of the line doubles while its impedance gets halved. Using this practice, congestion removal is done as follows.

1. Upgrade the congested line. Run OPF again. If the congestion is removed, then go to step 9.

2. If congestion still exists, then reset, i.e. cancel the upgrading of any line for the year in question.

3. Upgrade another line, then run OPF for congestion checking.

4. If the congestion is removed, then go to step 9 .

5. If congestion still exists, reset. Then repeat step 3 for all lines taking one line each time. Determine the set of lines that remove the congestion. Select upgrading the shortest line of that set as the decided congestion mitigation action. If the congestion is removed, then go to step 9 .

6. If congestion still exists, then repeat the previous step taking a combination of two lines each time.

7. Repeat for all possible line combinations. Determine the combinations of lines that remove the congestion. Select upgrading the lines combination of least upgrading 
cost as the decided congestion mitigation action. If the congestion is removed, then go to step 9.

8. If congestion still exists, then increase the number of lines in a combination by one. Repeat the previous step.

9. Continue the planning algorithm.

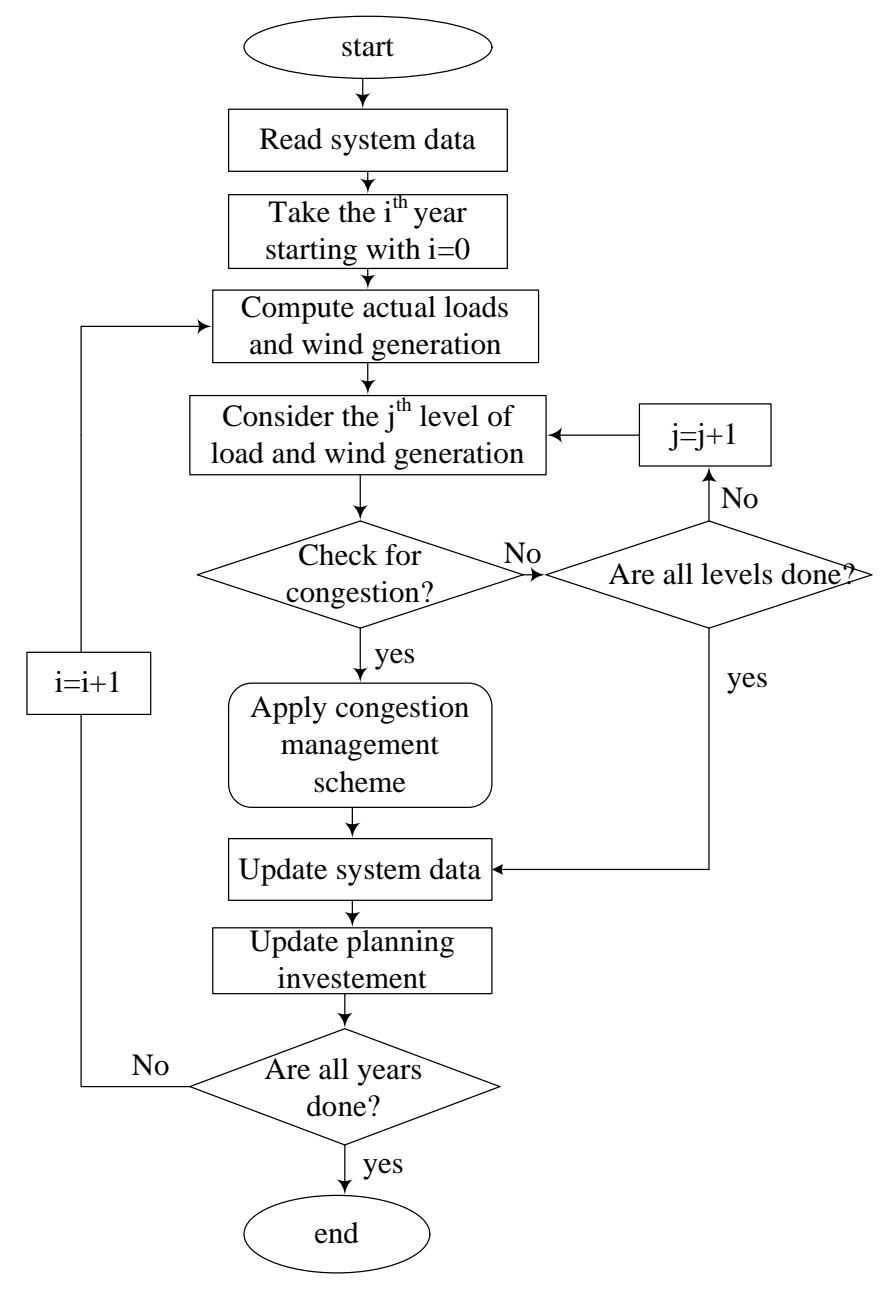

Figure (6): Flowchart for simulation methodology

B. Line upgrade in SW scenario

In the SW scenario, apart from the usual line upgrade, the utility also has the option of inserting DSR to mitigate congestion [5]. The transmission investment takes into account both the line upgrade plus the insertion of DSR. Using this practice, congestion removal is done as follows. 
1. Insert an increasing number of DSR units in the congested line(s) and run OPF again. If the congestion is removed, then continue the planning algorithm.

2. Identify a set A that includes the highest loaded one half of the lines number.

3. If congestion still exists, insert an increasing number of DSR units in one line. Run OPF to check congestion. Repeat for all lines of set A. Save each DSR-equipped line that removes congestion in a set B. Among the elements of B, select the line with least DSR units number as the decided congestion mitigation action. If the congestion is removed, then continue the planning algorithm.

4. If congestion still exists, insert an increasing number of DSR units in two lines of set A. Run OPF to check congestion. Repeat for all possible combinations of two lines of set A. Save each DSR-equipped two lines combination that removes congestion in a set C. From the set C, select the element with least DSR units number as the decided congestion mitigation action. If the congestion is removed, then continue the planning algorithm.

5. If congestion still exists, insert an increasing number of DSR units in three lines of set A. Run OPF to check congestion. Repeat for all possible combinations of three lines of set A. Save each DSR-equipped three lines combination that removes congestion in a set D. From the set D, select the element with least DSR units number as the decided congestion mitigation action. If the congestion is removed, then continue the planning algorithm.

6. If congestion still exists, perform line upgrade according to the BAU scenario as described above for one line.

7. Go to step 2 .

\section{Results:}

5.1 IEEE 39 bus system

The 10-generator and the 11-generator versions of the IEEE 39-bus system are evaluated. In case of BAU scenario, only line adding is presumed for upgrades. This line addition is expressed in terms of MW-miles. Tables 1, 2 demonstrate the annual transmission investments required in kilo MW-miles (GW-miles) from year 0 to year 19 for the 10-generator and 11-generator systems, respectively. The total transmission investment required for BAU scenario is about $1373 \mathrm{GW}$-miles and $145 \mathrm{GW}$-miles for the 10-generator and 11-generator systems, respectively. 
Table (1): Transmission upgrade investment for IEEE-39 bus 11-generator system by BAU

\begin{tabular}{|c|c|c|c|c|}
\hline Year & $\begin{array}{c}\text { Line } \\
\text { number }\end{array}$ & $\begin{array}{c}\text { Line } \\
\text { length } \\
\text { (miles) }\end{array}$ & $\begin{array}{c}\text { Capacity } \\
\text { added } \\
\text { (MW) }\end{array}$ & $\begin{array}{c}\text { MW_ } \\
\text { miles } \\
\text { (000s) }\end{array}$ \\
\hline $\mathbf{1 1}$ & $16--19$ & 121.85 & 600 & 73.11 \\
\hline $\mathbf{1 3}$ & $2--3$ & 94.39 & 500 & 47.195 \\
\hline $\mathbf{1 7}$ & $6--11$ & 51.24 & 480 & 24.595 \\
\hline \multicolumn{5}{|c}{ Total } \\
\hline
\end{tabular}

Table (2): Transmission upgrade investment for IEEE-39 bus 10- generator system by BAU

\begin{tabular}{|c|c|c|c|c|}
\hline Year & $\begin{array}{c}\text { Line } \\
\text { number }\end{array}$ & $\begin{array}{l}\text { Line } \\
\text { length } \\
\text { (miles) }\end{array}$ & $\begin{array}{c}\text { Capacity } \\
\text { added } \\
\text { (MW) }\end{array}$ & $\begin{array}{l}\text { MW__ } \\
\text { miles } \\
(000 s)\end{array}$ \\
\hline 5 & $16--19$ & 121.85 & 600 & 73.11 \\
\hline 7 & $2--3$ & 94.36 & 500 & 47.18 \\
\hline \multirow{2}{*}{12} & $6--11$ & 51.24 & 480 & 24.595 \\
\hline & $17--18$ & 51.24 & 600 & 30.744 \\
\hline \multirow{2}{*}{14} & $23--24$ & 218.71 & 600 & 131.23 \\
\hline & $22--35$ & 89.36 & 900 & 80.424 \\
\hline \multirow{7}{*}{18} & $25--26$ & 201.84 & 600 & 121.1 \\
\hline & $25--26$ & 201.84 & 1200 & 242.21 \\
\hline & $2--30$ & 113.12 & 900 & 101.81 \\
\hline & $10--11$ & 26.87 & 600 & 16.122 \\
\hline & $10--32$ & 124.98 & 900 & 112.48 \\
\hline & $19--33$ & 88.73 & 900 & 79.857 \\
\hline & $25--37$ & 145 & 900 & 130.5 \\
\hline \multirow{2}{*}{19} & $23--36$ & 88.73 & 900 & 79.857 \\
\hline & $20--34$ & 112.5 & 900 & 101.25 \\
\hline \multicolumn{4}{|c|}{ Total } & 1372.5 \\
\hline
\end{tabular}

It is noted that these two investment values are much different (about 9:1). This is due to the extra generator installed at bus 18 in the 11-generator system that leads to drastic variation in the power flows in the lines and hence in congestion conditions in both system versions. For the SW scenario, the upgrades permit both line upgrades and 
insertion of DSR units. To express DSR injection in terms of MW-miles, it is estimated that the cost of $1 \mathrm{MVA}$ of DSR is equivalent to that of $100 \mathrm{MW}$-miles. This is based on a MW-miles cost of $\$ 1000$ and an estimated DSR cost of \$100/kVA [5].

Tables 3, 4 illustrate the annual transmission investments required in kilo MW-miles from year 0 to year 19 by SW scenario. It is noted from Tables 3, 4 that most of the upgrades in the SW scenario involve only DSR injection. Thus, much lower investment cost of only $651 \mathrm{GW}$-miles for 10-generator and $74 \mathrm{GW}$-miles for 11-generator systems are required for this scenario.

Table (3): Transmission upgrade investment for IEEE-39 bus 11 generator system by DSR

\begin{tabular}{|c|c|c|c|c|c|}
\hline \multirow{2}{*}{ Year } & $\begin{array}{c}\text { Line } \\
\text { number }\end{array}$ & $\begin{array}{c}\text { Line } \\
\text { length } \\
\text { (miles) }\end{array}$ & $\begin{array}{c}\text { Capacity } \\
\text { added } \\
\text { (MW) }\end{array}$ & $\begin{array}{c}\text { DSR } \\
\text { injected } \\
\text { (MVA) }\end{array}$ & $\begin{array}{c}\text { MW } \\
\text { miles } \\
\text { (000s) }\end{array}$ \\
\hline $\mathbf{1 1}$ & $16--19$ & 121.85 & 600 & & 73.11 \\
\hline $\mathbf{1 3}$ & $6--11$ & & & 0.82 & 0.082 \\
\hline $\mathbf{1 4}$ & $2--3$ & & & 1.93 & 0.193 \\
\hline $\mathbf{1 5}$ & $2--3$ & & & 0.97 & 0.097 \\
\hline $\mathbf{1 6}$ & $2--3$ & & & 1.04 & 0.104 \\
\hline $\mathbf{1 7}$ & $2--3$ & & & 0.59 & 0.059 \\
\hline $\mathbf{1 8}$ & $2--3$ & & & 0.39 & 0.039 \\
\hline \multirow{2}{*}{$\mathbf{1 9}$} & $2--3$ & & & 1.42 & 0.142 \\
\cline { 2 - 6 } & $6--11$ & & & 2.9 & 0.29 \\
\hline \multicolumn{5}{|c|}{ Total } & \\
\hline
\end{tabular}

Figure 7 compares the transmission investments incurred in the BAU scenario with that of the SW scenario. It is evident that the SW can postpone and lessen the need for transmission line adding by installing DSRs. Hence, the total transmission investment required in the SW scenario is approximately $51 \%$ of that in the BAU scenario for the 11 -generator system and $47.5 \%$ for the 10 -generator system. Zero discount rate was used in calculation. The cost of MW-mile of building a new line increases from one year to the next. Meanwhile, the cost of DSR is expected to drop with time due to development in technology and mass production. Considering that factors can widen the cost difference between the two scenarios. The lead time of about 5 years required to build a new transmission line has been neglected in the analysis. In contrast, SW are expected to have much lower lead time in the order of few months. This gives a further 
advantage to SW scenario as it notably reduces the investment required in the short-term horizon.
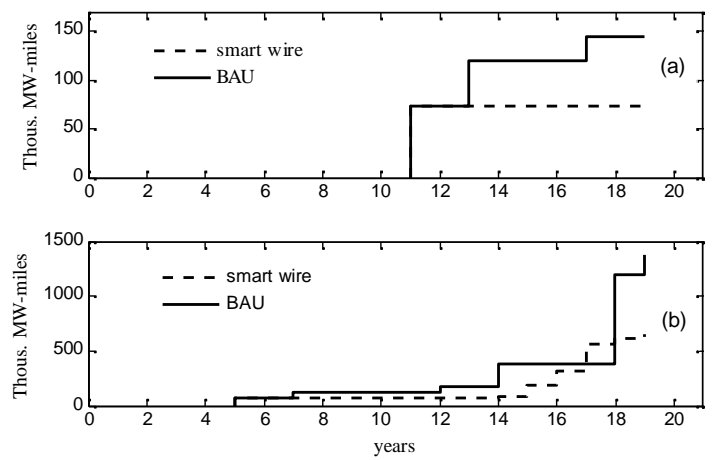

Figure (7): Comparison of transmission investment: BAU vs. Smart Wires Table (4): Transmission upgrade investment for IEEE 39-bus 10- generator system by DSR

\begin{tabular}{|c|c|c|c|c|c|}
\hline Year & $\begin{array}{c}\text { Line } \\
\text { number }\end{array}$ & $\begin{array}{l}\text { Line } \\
\text { length } \\
\text { (miles) }\end{array}$ & $\begin{array}{c}\text { Capacity } \\
\text { added } \\
\text { (MW) }\end{array}$ & $\begin{array}{c}\text { DSR } \\
\text { injected } \\
\text { (MVA) }\end{array}$ & $\begin{array}{l}\text { MW_ } \\
\text { miles } \\
(000 s)\end{array}$ \\
\hline 5 & $16--19$ & 121.86 & $\begin{array}{l}600 \\
\end{array}$ & & 73.12 \\
\hline 7 & $2--3$ & & & 2.3 & 0.23 \\
\hline \multirow{2}{*}{8} & $2--3$ & & & 2.971 & 0.297 \\
\hline & $9--39$ & & & 0.301 & 0.03 \\
\hline \multirow{2}{*}{9} & $2--3$ & & & 3.4552 & 0.346 \\
\hline & 9--39 & & & 0.18 & 0.018 \\
\hline 10 & $2--3$ & & & 4.84 & 0.484 \\
\hline \multirow{2}{*}{11} & $2--3$ & & & 4.15 & 0.415 \\
\hline & $9--39$ & & & 0.56 & 0.056 \\
\hline \multirow{2}{*}{12} & $2--3$ & & & 5.15 & 0.515 \\
\hline & $9--39$ & & & 0.59 & 0.059 \\
\hline \multirow{2}{*}{13} & $2--3$ & & & 6.48 & 0.648 \\
\hline & $9--39$ & & & 1.07 & 0.107 \\
\hline \multirow{3}{*}{14} & $2--3$ & & & 10.92 & 1.092 \\
\hline & $9--39$ & & & 1.32 & 0.132 \\
\hline & $25--26$ & & & 6.9 & 0.69 \\
\hline \multirow{2}{*}{15} & $2--3$ & & & 21.31 & 2.131 \\
\hline & $2--30$ & 113.12 & 900 & & 101.8 \\
\hline \multirow{2}{*}{16} & $2--3$ & & & 2.65 & 0.265 \\
\hline & $23--24$ & 218.72 & 600 & & 131.2 \\
\hline 17 & $25--26$ & 201.84 & 600 & & 121.1 \\
\hline
\end{tabular}




\begin{tabular}{|c|c|c|c|c|c||}
\cline { 2 - 6 } \multicolumn{1}{c|}{} & $25--37$ & 144.98 & 900 & & 130.5 \\
\hline \multirow{2}{*}{18} & $2--3$ & & & 3.04 & 0.304 \\
\cline { 2 - 6 } & $26--27$ & 91.86 & 600 & & 55.12 \\
\hline 19 & $17--18$ & 51.24 & 600 & & 30.74 \\
\hline \multicolumn{6}{|c|}{ Total } \\
\hline \hline \multicolumn{6}{|c|}{} \\
\hline
\end{tabular}

\subsection{IEEE 57-bus system}

This system is taken as one integrated area. The rest of assumptions and conditions made for the IEEE 39-bus system as stated in section 3 are adopted for the IEEE 57-bus system. The IEEE 57-bus system has a different topology, and different peak loads [18]. The total peak load is $1276 \mathrm{MW}$. The wind generation is assumed at buses 2, 3. The intra-day load variation and wind generation profiles are assumed similar to that of NW area shown in Figure 5. The algorithm discussed in section 4 above is applied to IEEE 57-bus system. Table 5 demonstrates the annual transmission investments required in kilo MW-miles from year 0 to year 19 by applying the BAU planning scenario.

Table (5): Transmission upgrade investment for IEEE 57-bus by BAU

\begin{tabular}{|c|c|c|c|c|}
\hline \multirow{2}{*}{ Year } & $\begin{array}{c}\text { Line } \\
\text { number }\end{array}$ & $\begin{array}{c}\text { Line } \\
\text { length } \\
\text { (miles) }\end{array}$ & $\begin{array}{c}\text { Capacity } \\
\text { added } \\
\text { (MW) }\end{array}$ & $\begin{array}{c}\text { MW_- } \\
\text { miles } \\
\text { (000s) }\end{array}$ \\
\hline $\mathbf{3}$ & $8--9$ & 18.635 & 200 & 3.727 \\
\hline $\mathbf{8}$ & $24--25$ & 222.44 & 200 & 44.487 \\
\hline $\mathbf{1 1}$ & $24--25$ & 222.44 & 400 & 88.974 \\
\hline $\mathbf{1 2}$ & $6--7$ & 37.64 & 200 & 7.528 \\
\hline $\mathbf{1 3}$ & $26--27$ & 93.725 & 200 & 18.745 \\
\hline $\mathbf{1 6}$ & $9--13$ & 58.305 & 200 & 11.661 \\
\hline $\mathbf{1 7}$ & $28--29$ & 21.66 & 200 & 4.332 \\
\hline $\mathbf{1 8}$ & $26--27$ & 93.725 & 400 & 37.49 \\
\hline \multicolumn{5}{|c}{ Total } \\
\hline
\end{tabular}

Table 6 illustrates the annual transmission investments required in kilo MW-miles from year 0 to year 19 by applying the SW planning scenario. The total transmission investment required is about $217 \mathrm{GW}$-miles for BAU scenario and only $77 \mathrm{GW}$-miles for the SW scenario. Hence, the total transmission investment required in the SW scenario is approximately $35.5 \%$ of that in the BAU scenario. 
5.3 Effect of changing wind generation conditions

To examine the effect of wind generation sizing on system planning, the rating of wind generation at bus 3 of the IEEE 57-bus system presented in section 5.2 above is changed in two cases. All other conditions are maintained as before. For the first case, the rating of wind generation at bus 3 is increased from $140 \mathrm{MW}$ to $180 \mathrm{MW}$. Figure 8 compares the lines upgrade investment of this modification to the base case in section 5.2 for BAU and SW scenarios.

For the second case, the rating of wind generation at bus 3 is decreased from $140 \mathrm{MW}$ to $100 \mathrm{MW}$. Figure 9 compares the lines upgrade investment of this modification to the base case in section 5.2 for BAU and SW scenarios.

Table (6): Transmission upgrade investment for IEEE 57-bus by DSR

\begin{tabular}{|c|c|c|c|c|c|}
\hline Year & $\begin{array}{c}\text { Line } \\
\text { number }\end{array}$ & $\begin{array}{c}\text { Line } \\
\text { length } \\
\text { (miles) }\end{array}$ & $\begin{array}{c}\text { Capacity } \\
\text { added } \\
\text { (MW) }\end{array}$ & $\begin{array}{c}\text { DSR } \\
\text { injected } \\
\text { (MVA) }\end{array}$ & $\begin{array}{c}\text { MW_ } \\
\text { miles } \\
\text { (000s) }\end{array}$ \\
\hline \hline $\mathbf{3}$ & $8--9$ & & & 8.08 & 0.808 \\
\hline \multirow{2}{*}{4} & $8--9$ & & & 6.92 & 0.692 \\
\cline { 2 - 6 } & $9--10$ & & & 1.26 & 0.126 \\
\hline \multirow{2}{*}{$\mathbf{5}$} & $8--9$ & & & 2.9 & 0.29 \\
\cline { 2 - 6 } & $9--10$ & & & 0.51 & 0.051 \\
\hline & $9--10$ & & & 0.55 & 0.055 \\
\hline $\mathbf{6}$ & $8--9$ & & & 2.88 & 0.288 \\
\hline $\mathbf{7}$ & $8--9$ & & & 0.33 & 0.033 \\
\hline $\mathbf{8}$ & $13--14$ & & & 2.47 & 0.247 \\
\hline $\mathbf{9}$ & $23--24$ & & & 0.82 & 0.082 \\
\hline $\mathbf{1 0}$ & $23--24$ & & & 1.06 & 0.106 \\
\hline $\mathbf{1 1}$ & $44--45$ & 45.83 & 200 & & 9.166 \\
\hline \multirow{2}{12}{} & $13--14$ & & & 0.58 & 0.058 \\
\hline & $13--15$ & & & 0.53 & 0.053 \\
\hline $\mathbf{1 3}$ & $24--25$ & 222.435 & 200 & & 44.49 \\
\hline $\mathbf{1 4}$ & $13--14$ & & & 12.23 & 1.223 \\
\hline $\mathbf{1 5}$ & $28--29$ & 21.66 & 200 & & 4.332 \\
\hline $\mathbf{1 7}$ & $13--14$ & & & 8.45 & 0.845 \\
\hline $\mathbf{1 8}$ & $13--49$ & 70.48 & 200 & & 14.1 \\
\hline
\end{tabular}



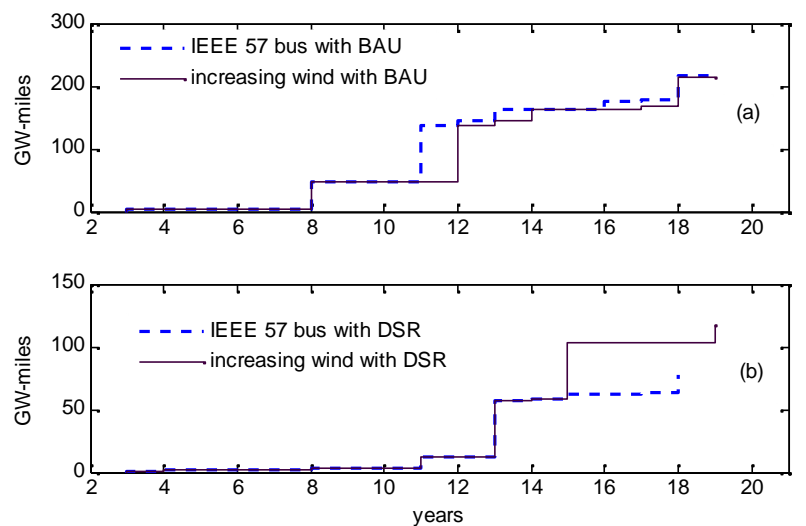

Figure (8): Effect of increasing wind penetration on transmission upgrade investment
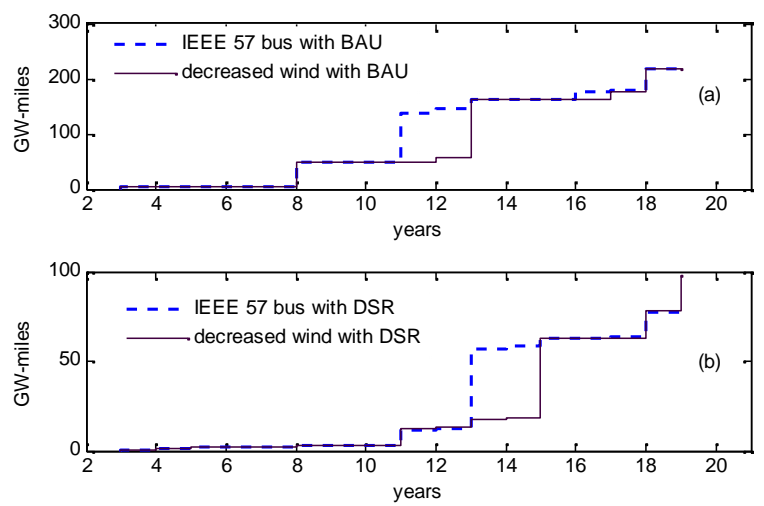

Figure (9): Effect of decreasing wind penetration on transmission upgrade investment

Furthermore, to examine the effect of wind generation location on system planning, the same wind generation of the IEEE 57-bus system presented in section 5.2 above is relocated at buses 6, 9 instead of buses 2, 3, respectively assuming identical wind characteristics for both locations. All other conditions are maintained as before. Figure10 compares the lines upgrade investment of this modification to the base case in section 5.2 for BAU and SW scenarios.

Table 7 compares the total lines upgrade investment cost of the three wind generation modifications to the base case in section 5.2 for BAU and SW scenarios. It is remarked that a small change in wind generation size by about $\pm 17 \%$ causes negligible change to the transmission upgrade investment for the BAU scenario. On the other hand, it tends to heighten the transmission upgrade investment for SW scenario. The transmission upgrade investments are obviously lower for SW scenario under all conditions. The percentage between the investment costs of the two scenarios is given in the fourth column of Table 7 . When the wind generation is relocated, the total transmission upgrade investment is very slightly lower by SW scenario. However, as can be seen in 
Figure 10b, the transmission upgrade investments for the two conditions are very close up to year 17 where building new lines is imperative to remove congestion for wind relocation conditions.
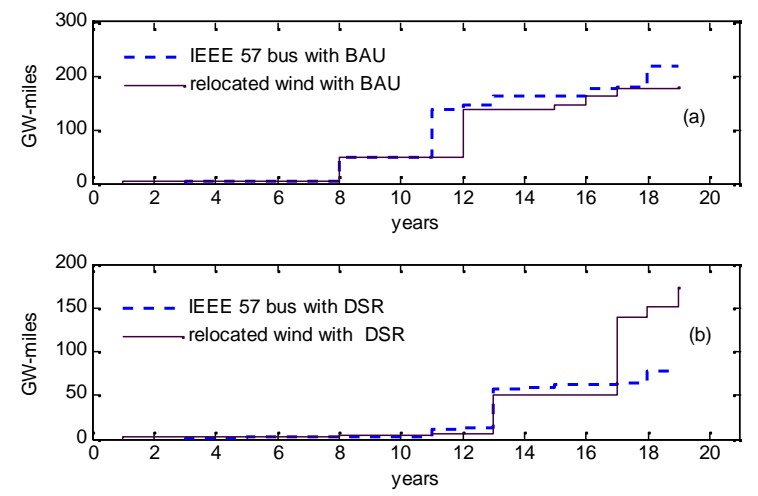

Figure (10): Effect of relocating wind generation on transmission upgrade investment

Table (7): Comparison of transmission upgrade investment for different wind generation conditions

\begin{tabular}{|c|c|c|c|}
\hline & $\begin{array}{c}\text { BAU } \\
\text { (GW-miles) }\end{array}$ & $\begin{array}{c}\text { DSR } \\
\text { (GW-miles) }\end{array}$ & $\%$ \\
\hline $\begin{array}{c}\text { IEEE 57 } \\
\text { bus }\end{array}$ & 216.94 & 77.04 & 35.5 \\
\hline $\begin{array}{c}\text { Wind } \\
\text { increase }\end{array}$ & 216.95 & 117.8 & 54.3 \\
\hline $\begin{array}{c}\text { Wind } \\
\text { decrease }\end{array}$ & 219.01 & 97.78 & 44.6 \\
\hline $\begin{array}{c}\text { Wind } \\
\text { relocate }\end{array}$ & 178.68 & 174.2 & 96.26 \\
\hline
\end{tabular}

\section{Conclusions:}

The distributed series reactor (DSR) has been presented as efficient, simple and low cost D-FACTS technology. The smart wires are defined as standard transmission lines that are augmented with a large number of DSRs. A proposed smart wire-based strategy for planning congestion-free power systems with increasing penetration level of wind generation is analyzed. Moreover, its potential to reduce the required investment for transmission system upgrading plan is assessed. The proposed approach is applied to the IEEE 39-bus and IEEE 57-bus test systems. Comparative analysis of results is provided for the classic and smart planning methods. It is proved that smart wire technology can help in removing congestion of power lines. So, it reinforces power systems to meet the 
increasing levels of demand and to accommodate increasing penetration levels of renewable generation with reduced upgrade investment.

\section{References:}

[1] J. Platts, "Impact of Regional Greenhouse Gas Initiative and Renewable Portfolio Standards on Power System Planning," IEEE Power Engineering Society General Meeting, 2006.

[2] M. Jacobs, "Transmission Recommendations for High Wind Penetration," IEEE Power Engineering Society General Meeting, 2007.

[3] D. Divan, J. Sastry, A. Prasai, H. Johal, "Thin AC Converters - A New Approach for Making Existing Grid Assets Smart and Controllable", IEEE Power Electronics Specialists Conference, PESC 2008, 15-19 June 2008, pp. $1695-1701$.

[4] D. Divan and H. Johal, "Distributed FACTS-A New Concept for Realizing Grid Power Flow Control," IEEE Trans. Power Electronics, Vol. 22, issue 6, pp.2253-2260, Nov. 2007.

[5] D. Das, F. Kreikebaum, D. Divan, and F. Lambert, "Reducing Transmission Investment to Meet Renewable Portfolio Standards Using Smart Wires," IEEE PES Transmission and Distribution Conference and Exposition, 2010, pp.1-7.

[6] A. Elmitwally and M. Rashed, "Flexible Operation Strategy for an Isolated PVDiesel Microgrid without Energy Storage," IEEE Trans. on Energy Conversion, Vol. 26, No. 1, pp. 235-244, March 2011.

[7] B. Bagen, D. Jacobson, G. Lane, H. Turanli, "Evaluation of the Performance of Back-to-Back HVDC Converter and Variable Frequency Transformer for Power Flow Control in a Weak Interconnection," IEEE Power Engineering Society General Meeting, June 2007.

[8] L. Gyugyi, C. Schauder, S. Williams, T. Rietman, D. Torgerson and A. Edris, "The Unified Power Flow Controller: A New Approach to Power Transmission Control," IEEE Transactions on Power Delivery, Vol. 10, No. 2, April 1995, pp. $1085-1097$.

[9] D. Divan, W. Brumsickle, R. Schneider, B. Kranz, R. Gascoigne, D. Bradshaw, M. Ingram, and I. Grant, "A Distributed Static Series Compensator System for Realizing Active Power Flow Control on Existing Power Lines," IEEE PSCE Conf. Records, Oct. 2004.

[10] D. Divan and H. Johal, "A Smarter Grid for Improving System Reliability and Asset Utilization," CES/IEEE 5th International Power Electronics and Motion Control Conference, 2006. 
[11] A. Saini and A. Saxena, "Optimal Power Flow Based Congestion Management Methods for Competitive Electricity Markets," International Journal of Computer and Electrical Engineering, Vol. 2, No. 1, Feb. 2010, pp. 73-80.

[12] M. Mandala and C. Gupta, "Comparative Studies of Congestion Management in Deregulated Electricity Market," 16th National Power Systems Conference, 15th-17th Dec., 2010.

[13] S. Nabavi1, A. Kazemi1, M. Masoum, "Social Welfare Improvement by TCSC using Real Code Based Genetic Algorithm in Double-Sided Auction Market," Advances in Electrical and Computer Engineering, Vol. 11, No. 2, 2011.

[14] K. Elango, S. Paranjothi, C. Sharmeela, "Transmission Congestion Management in Restructured Power Systems by Generation Rescheduling and Load Shedding using Rule Based OPF," European Journal of Scientific Research,Vol.57, No.3, 2011, pp.380-390

[15] E. Bompard, P. Correia, G. Gross, and M. Amelin, "Congestion-Management Schemes: A Comparative Analysis Under a Unified Framework," IEEE Transactions on Power Systems, Vol. 18, No. 1, Feb. 2003, pp. 346-352.

[16] L. Yao, P. Cartwright, L. Schmitt, X. Zhang, "Congestion Management of Transmission Systems Using FACTS," IEEE/PES Transmission and Distribution Conference \& Exhibition: Asia and Pacific, Dalian, China, 2005.

[17] X. Zhang, "Congestion Management -Challenges and Solutions," www. touchbriefings.com/pdf/2600/Zhang.pdf

[18] Power Systems Test Case Archive,

http://www.ee.washington.edu/research/pstca/ 
[19] R. Zimmerman, C. Murillo-Sánchez, MATPOWER Version 3.2 User's Manual, Sept. 2007, http://www.pserc.cornell.edu/matpower/ 